\title{
Pain management, prescription opioid mortality, and the CDC: is the devil in the data?
}

This article was published in the following Dove Press journal:

Journal of Pain Research

20 October 2017

Number of times this article has been viewed

\section{Michael E Schatman ${ }^{1,2}$ \\ Stephen J Ziegler ${ }^{3}$}

'Research and Network Development, Boston Pain Care, Waltham, MA,

${ }^{2}$ Public Health and Community

Medicine, Tufts University School of

Medicine, Boston, MA, ${ }^{3}$ Department of

Public Policy, Purdue University, Fort

Wayne, IN, USA
Correspondence: Michael E Schatman Public Health and Community Medicine, Tufts University School of Medicine, Boston, MA, USA Email michael.schatman@tufts.edu

\section{Introduction}

Transparency, freedom from bias, and accountability are, in principle, hallmarks of taxpayer-funded institutions. Unfortunately, it seems that at least one institution, the Centers for Disease Control and Prevention (CDC), continues to struggle with all three. What began with a prescribing guideline created in secrecy has now evolved to the use of statistical data and public statements that fail to capture not only the complexity of the problem but also the distinction between licit and illicit opioids and their relationship to the alarming increase in unintentional overdose. This is unfortunately consistent with Mark Twain's assertion that "There are lies, there are damn lies, and then there are statistics."

For instance, when the CDC was in the process of drafting guidelines for the use of long-term prescription opioids to treat chronic pain, the identities of the project's Core Expert Group members remained a secret until they were leaked. ${ }^{2,3}$ When its members were eventually identified, many were concerned that the group's composition was not balanced and had an inherent bias against the use of prescription opioids to treat pain. ${ }^{4}$ Then, when the time came for public input on the draft of the prescribing guideline, the CDC's invitation for meaningful comment can be best described as somewhere between a charade and a comedy of errors. For example, the only way the public could view the draft was during a one-time internet webinar. The actual guideline itself was not publicly available and was not posted on the CDC website, and admission to the webinar was limited. Those fortunate enough to gain entry were sometimes able to see the actual recommendation as it flashed on the screen, and while attendees were permitted to ask questions, the CDC stated that they would not provide any answers. At the end of the webinar, attendees could then email their comments to the CDC, but they only had 25 hours to do so. ${ }^{5}$ Due to the many technical problems associated with the first webinar (which was reminiscent of Get Smart's Cone of Silence), ${ }^{6}$ the CDC decided to repeat the webinar on the following day and allow an additional 24-hour comment period. ${ }^{4}$ But the controversy did not end there. Following the webinar, allegations of unlawful behavior by the $\mathrm{CDC}$ in the creation of the guideline were made, specifically that the CDC had violated the Federal Advisory Committee Act. ${ }^{7}$ The United States Congress eventually stepped in, and the CDC caved under pressure and permitted a 30-day open comment period ${ }^{8}$ during the Christmas holidays. Although the new open comment period yielded several thousand comments in the Federal Register, there was little change between the draft guideline and the final guideline. And while the CDC 
had asserted that they would be open to revising the guideline, and one of their own consultants had notified them that the guideline may be negatively impacting prescribing and pain treatment, there is no evidence that the CDC intends to do so. ${ }^{9}$ Remarkably, the actions of the CDC in the creation and publication of the prescribing guideline appears to violate every single standard that the Institute of Medicine recommended whenever clinical practice guidelines are created. ${ }^{10}$ Consequently, the authors of this commentary fear that the CDC's earlier lack of transparency, freedom from bias, and accountability in the creation of a prescribing guideline has now infected the way they characterize statistical data to the public regarding the relationship between opioids (licit and illicit) and unintentional overdose.

\section{Simplicity and data conflation is making the problem worse}

The United States is in the midst of an opioid crisis and prescribers and policymakers continue to struggle with how to effectively reduce the incidence of harm from prescription drugs while at the same time ensuring appropriate access. While accurate measurement of the degree by which various actors or variables have contributed to the initiation and prolongation of the current crisis remains challenging, it is fair to say that prescribers, policymakers, patients, nonpatients, the pharmaceutical industry, the insurance industry, regulators, illicit opioids, prescription opioids, dosage, ${ }^{11}$ and the addiction community have all played a role, whether in isolation or in combination with the above. While we do not believe that all actors or variables contributed equally to the present crisis, nor do we believe that the unintended negative outcomes flowing from their actions were intended, there is understandably one universal contributor to the increase in unintentional overdose that continues to be singled out by policymakers and the CDC: opioids. But the more important question becomes: about what opioids are they speaking? All opioids in general, some opioids in particular, illicit opioids such as heroin and illicitly manufactured fentanyl, or prescription opioids? These distinctions matter. According to the CDC, the "majority of drug overdose deaths (more than six out of ten) involve an opioid," 12 and "as many as 1 in 4 people who receive prescription opioids long term for noncancer pain in primary care settings struggles with addiction." ${ }^{13}$ Absent accompanying qualification of the statistics associated with these alarming statements, are they facially accurate or do they reflect a particular agenda - a campaign that fails to recognize the complexity of the issues, the factors, sources, and problems that once identified could help forge effective solutions? We believe it is the latter. The fol- lowing commentary examines some of the recent statistical claims asserted by the CDC and argues that not only are these statements inaccurate, but they also impede the ability of the public and policymakers to understand the complexity of the problem and create solutions that are balanced and effective. In brief, while prescription opioids continue to play a part in the crisis, illicit opioids such as heroin and illicitly manufactured fentanyl, not prescription opioids and overprescribing, are currently the driving forces behind the increase in unintentional overdose deaths in the United States. This critical distinction is often ignored or underappreciated by the press and policymakers, and is a distinction that needs to be emphasized by the CDC. The failure to do so has far-reaching consequences in terms of policy, pain treatment, substance abuse prevention, and reduction of unintentional overdose.

\section{Prescribing: is the problem under- or over-prescribing?}

The Institute of Medicine has estimated that over 100 million Americans suffer from chronic, long-term pain. ${ }^{14}$ Pain is individualized, and so should be its treatment. Opioids can be effective in treating pain, and while there may be a variety of alternatives to opioids, some may not be as effective or covered by insurance reimbursement. Yet despite the millions of people who suffer from chronic pain in the United States, there is scant evidence that the CDC considers chronic pain a serious public health problem. For instance, the CDC maintains an $\mathrm{A}-\mathrm{Z}$ index on their public website, an index of "topics with relevance to a broad cross-section of CDC.gov's audiences" that "are representative of popular topics [.. . ] or have critical importance to CDC's public health mission.." ${ }^{15} \mathrm{~A}$ search using the $\mathrm{A}-\mathrm{Z}$ index under the letter " $\mathrm{C}$ " found references to chronic conditions, but chronic pain was not one of them; a search using the letter "P" found only two topics containing the word "pain": Pain Killer OD, and Pain Killer Overdose. ${ }^{16}$ While undertreated pain does not seem to be of critical importance to the $\mathrm{CDC}$, that has not prevented them from creating a prescribing guideline to treat pain, recommending against the use of prescription opioids, and asserting that nonpharmacologic therapy is preferred. ${ }^{17}$

But whether pain is treated with or without prescription opioids, one thing seems clear: it has been undertreated for decades. Although myriad reasons for undertreatment exist, decades ago many well-intentioned health care providers responded to this public health crisis by increasing their prescribing of opioids. While more prescription drugs were made available to treat pain, it undoubtedly increased the likelihood of leftover medication which in turn increased the potential for misuse, abuse, and diversion. In fact, studies continue to 
provide evidence that a small percentage of individuals who started using heroin began by misusing prescription drugs (whether they were the drugs they were originally prescribed or someone else's), so regardless of how one characterizes over- and underprescribing, there should always be efforts aimed at reducing the amount of leftover medication since the common source of diverted pharmaceuticals is a friend or relative. ${ }^{18}$

So, what amount of prescribing is appropriate? This represents a difficult question since one size does not fit all. A particular type or dose of one medication may be appropriate for one patient and condition and wholly inappropriate for someone else. Yet despite the medical necessity of tailoring treatments to the individual, the tendency today is for an acrossthe-board reduction in prescription opioid availability. We can certainly understand the calls for reduction in the surgical context if one considers emerging evidence that a substantial portion of prescription pain medication goes unused by patients in the perioperative care setting. ${ }^{19}$ But is prescription pain medication the driving force in today's overdose epidemic, and if not, does an across-the-board reduction in opioid availability and prescribing make sense? We recognize that an excessive supply of prescription opioids can create serious public health problems, much like the overprescribing of antibiotics can have micro and macro health concerns. But are prescribers prescribing more, or less than they used to? According to the $\mathrm{CDC}$ and several states' Departments of Health, less opioids are being prescribed, which in turn indicates that there may be something other than just prescription opioids that are contributing to the escalation in unintentional overdose.

Data from the CDC indicate that between 2010 and 2015, the amount of opioids prescribed in the United States actually decreased by more than $18 \%$, with a $13.1 \%$ decrease reported between 2012 and 2015 alone. ${ }^{20}$ Survey data also suggest that more than half of physicians in the United States have reduced their opioid prescribing, with nearly $10 \%$ having stopped prescribing opioids altogether. ${ }^{21}$ Although more recent federal data on the decrease in opioid prescribing are not available, state data are helpful. For example, in Tennessee between 2015 and 2016, the total amount of opioids prescribed decreased by another $9.2 \% .{ }^{22}$ In New Mexico, the Department of Health reported that the amount of opioids prescribed decreased by 5\% from the first quarter of 2016 to the first quarter of $2017 .{ }^{23}$ In terms of prescriptions filled, Michigan reported a 9.7\% decrease between 2015 and 2016, Maine reported an 11.9\% decrease, Massachusetts reported a $12.7 \%$ decrease, West Virginia reported a $15.6 \%$ decrease, and so on. ${ }^{24}$ In fact, perusal of the data from the study ${ }^{24}$ indicated that every state (with the exception of Florida) and the District of Columbia reported a decrease in the number of opioid prescriptions written between 2015 and 2016. Consequently, there is little doubt that the amount of opioids being prescribed is decreasing dramatically, so it would be disingenuous to suggest otherwise. While the rate of prescribing continues to decline, what about the trends in prescription opioid mortality? Are they declining as well? This question is a more complex one, and thus needs to be considered carefully.

\section{Measuring and reporting prescription opioid mortality}

What constitutes "a prescription opioid death?" It appears that there is some disagreement and controversy regarding this issue, ${ }^{25,26}$ a disagreement that may be agenda-driven or subject to bias. In 2009, to its credit, the CDC reported that the tremendous variation between states' rates of prescription opioid overdose deaths "should be interpreted with caution as there is some variation in the reporting of substances on death records." ${ }^{27}$ This is an understatement. Determining therapeutic levels and causes of unintentional overdose can be challenging, and postmortem drug redistribution has been described as a toxicological nightmare. ${ }^{28}$ Although there is a need for more consistency between coroners and medical examiner offices across the United States when opioid-related deaths are involved, ${ }^{29,30}$ many states utilize death certificate data, which often do not include the source of a drug, the purpose for which the drug was used, the level of opioid tolerance in the decedent, and even the specific type or the name of the $\operatorname{drug}(\mathrm{s})$ that were involved. ${ }^{31} \mathrm{~A}$ recent study ${ }^{32}$ looked at "fentanyl deaths" in southeastern Massachusetts, with the authors of that study determining that $82 \%$ of the fentanyl deaths over a 6-month period from 2014 to 2015 were likely due to illicitly manufactured fentanyl, with only $4 \%$ attributed to legal, pharmaceutical fentanyl. It is important to note that carfentanil, a common contaminate, has $100 \times$ the potency of fentanyl. Extrapolating from the reported figures, only a mere $5 \%$ of all "fentanyl" overdose deaths were due to a legal, pharmaceutical product, with the remaining 14\% due to "an unknown source of fentanyl." It is important to note, however, that Rudd et a ${ }^{33}$ warned in a 2016 article that "illicitly manufactured fentanyl cannot be distinguished from prescription fentanyl in death certificate data," suggesting that this problem is widespread. In other words, if only $5 \%$ of all "fentanyl overdose deaths" are due to pharmaceutical fentanyl, and fentanyl (defined broadly) is now responsible for approximately $79 \%$ of all "prescription 
opioid overdose" and "fentanyl" deaths (extrapolating from 2016 Maryland data) ${ }^{34}$ could the number of actual prescription opioid deaths be only a small percentage of the overall opioid overdose statistics? This is not only a measurement problem; this becomes a policy and solution problem if the public and policymakers continue to fixate on prescription opioids as the problem and the primary factor involved in unintentional overdose.

In order to more accurately assess the actual number of prescription opioid analgesic deaths, it was necessary for the first author (MES) to go to individual states' Departments of Health (DOH). Looking at the data from Illinois, what were listed as deaths due to "Opioid Analgesics" reportedly increased from 589 to 1233 between 2015 and 2016. ${ }^{35}$ This $107 \%$ increase appeared extremely curious given the aforementioned decrease in opioid prescribing. In speaking to one of DOH's statisticians, he confirmed our suspicion: This dramatic increase was almost completely driven by illicit fentanyl and its potent analogs, not by legitimate pharmaceutical opioids used to treat pain. Furthermore, he noted that irrespective of the number of dangerous substances that are found in toxicology reports, the state's death certificate data categorize any death in which even an iota of a prescription opioid (or a nonpharmaceutical fentanyl product) is found as a "prescription opioid death" (J Tharp, personal communication, September 22, 2017). A number of other states (eg, Maryland, New Hampshire) have recently taken the initiative to delineate between fentanyl (generally illicit) and other prescription opioid deaths. So, for example, New Hampshire's Department of Health data characterizes opioid deaths as attributable to specific legitimate prescription opioids, prescription opioids in combination with other licit and illicit drugs (including benzodiazepines, cocaine, methamphetamine and alcohol; methadone, oxycodone, hydrocodone, morphine, tramadol, and oxymorphone) (S Watkins, personal communication, September 22, 2017). A total of 59 deaths involving a legitimate prescription opioid were recorded, with 32 involving oxycodone. However, $72 \%$ of the deaths involving oxycodone included alcohol, a benzodiazepine (or both alcohol and a benzodiazepine), kratom, methamphetamine, or another prescription opioid (which may or may not have been prescribed concurrently). These data strongly suggest not a "prescription opioid crisis" but rather a "polypharmacy crisis."

The role of polypharmacy in "prescription opioid overdose deaths" was recently elucidated empirically. ${ }^{36}$ The investigators determined that more than half of decedents with an opioid-positive toxicology had alcohol in their systems, and the average number of drugs identified in the toxicologies was six. The second most commonly used drug associated with mortality in New Hampshire was methadone, which was involved in 18 deaths - more than half of which involved other substances as well. The relatively high number of methadone-associated deaths is not surprising, certainly given the literature supporting the high level of potential lethality of this drug and its questionable suitability for use in treating chronic noncancer pain, especially for the inexperienced clinician that continues or initiates methadone, most particularly due to complex pharmacokinetics and unanticipated drug interactions. ${ }^{37}$ In fact, many in the pain community continued to express concern over the placement of methadone on Washington State's formulary list to treat pain. Washington State officials defended the placement of methadone on the preferred drug list to treat pain, but it was not until the Seattle Times examined the escalation in overdose and its ties to methadone that the state revisited the matter. ${ }^{38}$ Consequently, a deeper analysis of the existing data helps reveal the complexity of the issue and what is really behind the current opioid crisis.

Yet another cause of the unfortunate overestimation of opioid mortality in the United States (and its link to prescription pain medication) relates to difficulties in distinguishing between heroin and morphine in postmortem samples. Heroin is twice as potent as morphine, has a half-life of only 6-25 minutes prior to its metabolism to morphine in the liver, ${ }^{39}$ resulting in studies suggesting that heroin deaths are also underestimated while morphine deaths are overestimated in their prevalence. ${ }^{40,41}$ Given that the prescription opioid epidemic of the past is progressively being replaced by a surge in heroin use, ${ }^{42}$ the negative implications for inaccurate reporting that misidentifies a commonly prescribed opioid that has analgesic efficacy when used appropriately are clear. Compounding the problem is that heroin is frequently laced with illicit, nonpharmaceutical fentanyl products, ${ }^{43}$ resulting in coroners' reports now often yielding inaccurate data suggesting that addicts are succumbing to the effects of not just one prescription opioid but two.

Nevertheless, despite the data and their shortcomings, the CDC continues to claim that we are in the midst of a prescription opioid crisis. As their most recent published data suggest that "In 2015, more than 15,000 people died from overdoses involving prescription opioids," ${ }^{, 4}$ one of the authors [MES] submitted a formal request for more recent data. The CDC responded by stating that it would be "addressed in a timely manner." As of the time of writing of the present commentary, this still has not occurred. 
The concern is this: for the CDC to suggest that more than 15,000 died in that year from "prescription opioids" when a closer examination of the data indicates that illicit opioids and/or polypharmacy were involved is not only inaccurate and disingenuous, it can negatively impact patients who are well-managed on long-term opioid therapies and have no effective safe alternatives that are covered by insurance, negatively impact health care providers who seek to relieve suffering, and negatively impact people who are suffering from substance use disorders.

\section{The necessity of balance}

In medicine, as in life, there are risks and benefits. Prescription opioids can bring enormous benefits to those who are suffering from acute or chronic long-term pain. Prescribed appropriately, prescription pain medication has provided relief to millions of Americans; it has increased their quality of life, improved their function, provided an option to those for which other analgesics are contraindicated due to certain medical conditions, and reduced their suffering. At the same time, however, prescription opioids by their chemical nature are susceptible to abuse, misuse, and physical harm, particularly among certain subgroups of the population. Yet in today's environment, the narrative is not about how to balance the need to ensure access while preventing abuse, nor is it about the people suffering from acute or chronic pain requiring long-term opioids. Rather, it is about opioids, their misuse and abuse, and the increase in unintentional overdose. The proposed solution by policymakers to this complex problem has often been simple: just say no to drugs, and those who are struggling with addiction simply need to be enrolled in a substance abuse program so that they can become clean again. But things are not so easy. Despite decreases in the prescribing of prescription opioids, we continue to see an increase in the rates of unintentional overdose. While there is clear evidence that this increase is driven by the use of illicit opioids such as heroin or illicitly manufactured fentanyl derivatives, this particular fact continues to get lost in the shuffle and results in knee-jerk reactions calling for the reduction of both the supply and use of prescription opioids. People who are not adequately treated for their pain will seek out alternatives, often harmful alternatives that can lead to addiction, unintentional overdose, or even suicide.

\section{Conclusion}

It is easy to demonize and point fingers at industry, prescribers, or anyone who calls into question the newest battle in the never-ending war on drugs. While we would agree that anyone involved in the distribution of illicit drugs such as heroin and illicitly manufactured fentanyl derivatives should be stopped from harming others, and the misuse and abuse of prescription opioids have played a role in the problems we see today, in the right hands prescription opioids can help eliminate human suffering. Prescription opioids are not the panacea, but they have medicinal benefits, unlike tobacco. For instance, according to the CDC, "cigarette smoking is responsible for more than 480,000 deaths per year in the United States, including more than 41,000 deaths resulting from secondhand smoke exposure." ${ }^{45}$ In contrast to appropriately prescribed and administered opioids, we are unaware of any legitimate medical treatments involving the use of cigarettes, a product that continues to be available to anyone over 18 years without a prescription.

Is there anything that can be done to help solve the opioid crisis? We believe so. First, we would suggest that the CDC refrain from making alarmist statements that cite statistics that are not supported by the evidence without qualification. As noted earlier, a recent web-based publication by the CDC cited an alarming statistic in support of its campaign to reduce addiction and unintentional overdose: "As many as 1 in 4 people who receive prescription opioids long term for noncancer pain in primary care settings struggles with addiction." ${ }^{46}$ While the study cited by the CDC (appearing as Footnote number 7 in the CDC publication) was an important contribution to the field, the authors of the study, unlike the CDC publication, correctly noted the study's limitations and the difficulty in generalizing the results:

Study limitations include that our diagnostic data were based on patient self-report; that our survey completion rate was less than optimal, thus study estimates may be biased; and, as patients were drawn from a predominately Caucasian population in one US region, it may not be possible to generalize these findings. ${ }^{47}$

Second, the CDC should recognize that chronic pain impacts millions of people in the United States and should, at a minimum, create an entry for pain on their website's A-Z index. We are concerned that the absence of information about the millions of Americans who suffer from chronic pain sends the message that pain does not "have critical importance to CDC's public health mission." Creating the link and providing information on this serious health problem will go a long way to bringing about balance.

Finally, we need to find ways to work together, instead of against each other, emphasizing civil discourse instead of finger pointing. We are concerned that some people who 
are intent on blaming prescribers, patients, and the pharmaceutical industry for the problem without offering solutions (other than perhaps eliminating prescription opioids) are making it more about them than the people they are actually trying to help. We have many problems, but there are also many solutions.

And while we are also concerned that the message about the opioid crisis is not accurately depicted in the media, we close with an interesting observation from a journalist that may be helpful to all of us. Malcolm Gladwell, a Canadian journalist, recently commented that the "one thing that continues to baffle me about American society is how Americans love to accentuate how they are different from each other. Whereas in Canada, all we do is celebrate what we have in common." 48

Maybe we should give that a try and find that common ground that unites all of us in achieving better outcomes not only in reducing abuse and harm but also in treating pain.

\section{Disclosure}

Dr Ziegler has served as a paid consultant to both government and the pharmaceutical industry on matters involving pain treatment, prescription drugs, and policy. Dr Schatman serves as a consultant to Depomed.

\section{References}

1. Twain M. Chapters from my autobiography -XX. N Am Rev. 1907; $185: 465-474$.

2. Samp R. CDC Bows To Demands For Transparency And Public Input On Draft Opioid-Prescribing Guidelines. Forbes. $2015 \mathrm{Dec}$ 15. Available at: https://www.forbes.com/sites/wlf/2015/12/15/ cdc-bows-to-demands-for-transparency-and-public-input-on-draftopioid-prescribing-guidelines/\#2d071b2a135b. Accessed September 28, 2017.

3. Anson P. PROP Helped Draft CDC Opioid Guidelines. Pain News Network. 2015 Sept 21. Available at: https://www.painnewsnetwork. org/stories/2015/9/21/prop-helped-draft-cdc-opioid-guidelines. Last accessed September 28, 2017.

4. McCoy S. Dysfunction, Lobbying, and Conflict of Interest in the Debate Over Opioids. Inside Sources. 2015 Oct 15. http://www.insidesources. $\mathrm{com} /$ dysfunction-lobbying-and-conflict-of-interest-in-the-debate-overopioids/. Accessed September 28, 2017.

5. S.564 Comprehensive Addiction and Recovery Act of 2016. Congress. gov. Available from https://www.congress.gov/bill/114th-congress/ senate-bill/524/text. Accessed October 15, 2017.

6. Ziegler SJ. CDC's Prescribing Guidelines and the "Cone of Silence". Pain News Network. 2015 Oct 15. Available at: https://www.painnewsnetwork.org/stories/2015/10/13/cdcs-prescribing-guidelines-and-thecone-of-silence. Accessed September 28, 2017.

7. Anson P. CDC Accused of "Blatant Violations" of Federal Law. Pain News Network. 2015 Nov 18. Available at: https://www.painnewsnetwork.org/stories/2015/11/18/legal-foundation-accuses-cdc-of-blatantviolations-of-federal-law?rq=core $\% 20$ expert $\% 20$ group. Accessed, September 28, 2017.

8. Congress.gov. Comprehensive Addiction and Recovery Act of 2016. Available at: https://www.congress.gov/bill/114th-congress/senatebill/524/text. Accessed October 1, 2017.
9. Anson P. CDC Ignored Warning about Opioid Guidelines. Pain News Network. 2017 Sept 5. Available at https://www.painnewsnetwork. org/stories/2017/9/5/cdc-ignored-warnings-about-opioid-guidelines Accessed September 28, 2017.

10. Institute of Medicine. Clinical Practice Guidelines We Can Trust. Washington, DC: National Academies Press; 2011. Available at https://www. ncbi.nlm.nih.gov/books/NBK209538/. Accessed October 1, 2017.

11. Ziegler SJ. The proliferation of dosage thresholds in opioid prescribing policies and their potential to increase pain and opioid-related mortality. Pain Med. 2015;16(10):1851-1856.

12. Centers for disease Control and Prevention. Understanding the Epidemic. Record Overdose Deaths. Available at https://www.cdc.gov/ drugoverdose/epidemic/index.html. Accessed September 25, 2017.

13. Centers for Disease Control and Prevention. Prescription Opioid Overdose Data, Additional Risks. Available at https://www.cdc.gov/ drugoverdose/data/overdose.html. Accessed September 15, 2017.

14. Institute of Medicine. Relieving Pain in America: A Blueprint for Transforming Prevention, Care, Education, and Research. Washington, DC: The National Academies Press, 2011.

15. Centers for Disease Control and Prevention. A-Z FAQ. Available at https://www.cdc.gov/az/azfaq.html\#whatitems. Accessed September 26, 2017.

16. Centers for Disease Control and Prevention. CDC A-Z Index. Available at https://www.cdc.gov/az/p.html. Accessed October 1, 2017.

17. Centers for Disease Control and Prevention. Dowell D, Haegerich TM, Chou R. CDC Guideline for Prescribing Opioids for Chronic Pain United States, 2016. MMWR Recomm Rep 2016;65(No. RR-1):1-49. Available at http://dx.doi.org/10.15585/mmwr.rr6501e1.

18. Inciardi JA, Surratt HL, Cicero TJ, et al. The "Black Box" of prescription drug diversion. J Addict Dis. 2009;28(4):332-347.

19. Bonnette M, Malik I, Bottros M. A gathering storm: are perioperative opioids problematic? 2017; PWJ, 5 (1):26-33.

20. Guy GP Jr, Zhang K, Bohm MK, et al. Vital signs: changes in opioid prescribing in the United States. 2006-2015. MMWR Morb Mortal Wkly Rep. 2017;66:697-704.

21. Freyer FJ. Doctors are cutting opioids, even if it harms patients. Boston Globe, January 3, 2017. Available at: https:/www.bostonglobe.com/ metro/2017/01/02/doctors-curtail-opioids-but-many-see-harm-painpatients/z4Ci68TePafcD9AcORs04J/story.html. Accessed September 17, 2017.

22. The Sycamore Institute. Policy Brief, August 3, 2017: The opioid epidemic in Tennessee. Part 1 of 3 . Key policy milestones and indicators of progress. Available at: http:/www.sycamoreinstitutetn.org/ wp-content/uploads/2017/08/2017.08.03-FINAL-Opioids-in-TN1-of-3-Policy-Milestones-and-Progress.pdf. Accessed September 17, 2017.

23. New Mexico Department of Health. Opioid prescriptions significantly decline in New Mexico. July 12, 2017. Available at: https://nmhealth. org/news/information/2017/7/?view=581. Last accessed September 17, 2017.

24. Xponent, QuintilesIMS data. Danbury, CT. State and National totals of retail filled prescriptions: all opioid analgesics 2013-2016. 2017. Available at: http://www.cmanet.org/files/assets/news/2017/04/imsopioid-study-2017.pdf. Accessed September 17, 2017.

25. Webster LR, Cochella S, Dasgupta N, et al. An analysis of the root causes for opioid-related overdose deaths in the United States. Pain Med. 2011; 12, S26-S35.

26. Webster LR, Dasgupta N. Obtaining adequate data to determine causes of opioid-related overdose deaths. Pain Med. 2011;12:S86-S92.

27. Warner M, Chen LH, Makuc DM. Increase in fatal poisonings involving opioid analgesics in the United States, 1999-2006. NCHS Data Brief. 2009;(22):1-8.

28. Pounder DJ, Jones GR. Post-mortem Drug Redistribution - a toxicological nightmare. Forensic Sci Int. 1990;45:253-263.

29. Committee on Identifying the Needs of the Forensic Sciences Community, National Research Council. Strengthening Forensic Science in the United States: A Path Forward., Washington, DC: National Academies Press. 2009. 
30. Davis GG. National Association of Medical Examiners, \& American College of Medical Toxicology. Recommendations for the Investigation, Diagnosis, and Certification of Deaths Related to Opioid Drugs. Acad Forensic Pathol. 2013;3(1):63-76.

31. Nordstrom DL, Yokoi-Shelton ML, Zosel A. Using multiple cause-ofdeath data to improve surveillance of drug-related mortality. J Public Health Manag Pract. 2013;19:402-411.

32. Somerville NJ, O'Donnell J, Gladden RM, et al. Characteristics of fentanyl overdose - Massachusetts, 2014-2016. MMWR Morb Mortal Wkly Rep. 2017;66:382-386.

33. Rudd RA, Aleshire N, Zibbell JE, Gladden RM. Increases in drug and opioid overdose deaths - United States, 2000-2014. MMWR Morb Mortal Wkly Rep. 2016;64:1378-1382

34. Maryland Department of Health and Mental Hygiene. Drug- and Alcohol-Related Intoxication Deaths in Maryland, 2016. Available at: https://bha.health.maryland.gov/OVERDOSE_PREVENTION/Documents/Maryland\%202016\%20Overdose\%20Annual\%20report.pdf. Accessed September 22, 2017.

35. Illinois Department of Public Health. Drug Overdose Deaths by Sex, Age Group, Race/Ethnicity and County, Illinois Residents, 2013-2016. September 5, 2017. Available at http://www.dph.illinois.gov/sites/ default/files/publications/Drug-Overdose-Deaths-September2017.pdf. Accessed September 22, 2017.

36. Hannah HA, Arambula K, Ereman R, Harris D, Torres A, Willis M. Using local toxicology data for drug overdose mortality surveillance. J Public Health Inform. 2017;9(1):e143.

37. Ray WA, Chung CP, Murray KT, Cooper WO, Hall K, Stein CM. Outof-hospital mortality among patients receiving methadone for noncancer pain. JAMA Intern Med. 2015;175:420-427.

38. Methadone and the Politics of Pain. Seattle Times, April 30, 2012. Available at: http://old.seattletimes.com/flatpages/specialreports/methadone/ methadoneandthepoliticsofpain.html.
39. Inturrisi CE, Max MB, Foley KM, Schultz M, Shin S-U, Houde RW. The pharmacokinetics of heroin in patients with chronic pain. $N$ Engl J Med. 1984;310:1213-1217.

40. Mertz KJ, Janssen JK, Williams KE. Underrepresentation of heroin involvement in unintentional drug overdose deaths in Allegheny County, PA. J Forensic Sci. 2014;59:1583-1585.

41. Warner M, Paulozzi LJ, Nolte KB, et al. State variation in certifying manner of death and drugs involved in drug intoxication deaths. Acad Forensic Pathol. 2013;3:231-237.

42. Hedegaard H, Warner M, Minino AM. Drug Overdose Deaths in the United States, 1999-2015. NCHS Data Brief. 2017 Feb;(273):1-8.

43. Moore PQ, Weber J, Cina S, Aks S. Syndrome surveillance of fentanyllaced heroin outbreaks: utilization of EMS, Medical Examiner and Poison Center databases. Am J Emerg Med. 2017 May 8 [Epub ahead of print].

44. Centers for Disease Control and Prevention. Prescription Opioid Overdose Data. Available at: https:/www.cdc.gov/drugoverdose/data/ overdose.html. Accessed September 22, 2017.

45. Centers for Disease Control and Prevention. Smoking and Tobacco Use Available at https://www.cdc.gov/tobacco/data_statistics/fact_sheets/ fast_facts/index.htm. Accessed October 1, 2017.

46. Centers for Disease Control and Prevention. Prescription Opioid Overdose Data, Additional Risks. Available at https://www.cdc.gov/ drugoverdose/data/overdose.html. Accessed September 15, 2017.

47. Boscarino JA, Rukstalis M, Hoffman SN, et al. Risk factors for drug dependence among out-patients on opioid therapy in a large US healthcare system. Addiction. 2010; 105(10):1776-1782.

48. Gladwell M. Meet the Press (transcript). July 2, 2017. Available at http:// nbcnews.to/2tgPcDG. Accessed July 5, 2017.

Dove Medical Press encourages responsible, free and frank academic debate. The content of the Journal of Pain Research 'Editorial' section does not necessarily represent the views of Dove Medical Press, its officers, agents, employees, related entities or the Journal of Pain Research editors. While all reasonable steps have been taken to confirm the content of each Editorial, Dove Medical Press accepts no liability in respect of the content of any Editorial, nor is it responsible for the content and accuracy of any Editorial.

Journal of Pain Research

\section{Publish your work in this journal}

The Journal of Pain Research is an international, peer reviewed, open access, online journal that welcomes laboratory and clinical findings in the fields of pain research and the prevention and management of pain. Original research, reviews, symposium reports, hypothesis formation and commentaries are all considered for publication.

\section{Dovepress}

The manuscript management system is completely online and includes a very quick and fair peer-review system, which is all easy to use. Visit http://www.dovepress.com/testimonials.php to read real quotes from published authors. 